\title{
Should I stay or should I go? Mycorrhizal plants are more likely to invest in long-distance seed dispersal than non-mycorrhizal plants
}

\author{
Marta Correia, ${ }^{1 *}$ (iD) Ruben \\ Heleno, ${ }^{1}$ iD Pablo Vargas ${ }^{2}$ \\ and Susana Rodríguez- \\ Echeverría ${ }^{1}$ \\ ${ }^{1}$ CFE - Centre for Functional Ecol- \\ ogy Department of Life Sciences \\ University of Coimbra Calçada \\ Martim de Freitas, Coimbra 3001- \\ 456, Portugal \\ ${ }^{2}$ Real Jardín Botánico de Madrid \\ (RJB-CSIC) Plaza de Murillo 2, \\ Madrid 28014, Spain \\ *Correspondence: E-mail: correio. \\ marta@gmail.com
}

\begin{abstract}
Seed dispersal and mycorrhizal associations are key mutualisms for the functioning and regeneration of plant communities; however, these processes have seldom been explored together. We hypothesised that obligatory mycorrhizal plants will be less likely to have long-distance dispersal (LDD) syndromes since the probability of finding suitable mycorrhizal partners is likely to decrease with distance to the mother plant. We contrasted the mycorrhizal status and LDD syndromes for 1960 European plant species, using phylogenetically corrected log-linear models. Contrary to our expectation, having specialised structures for LDD is more frequent in obligate mycorrhizal plants than in non-mycorrhizal plants, revealing that lack of compatible mutualists does not constrain investment in LDD structures in the European Flora. Ectomycorrhizal plants associated with wind-dispersing fungi are also more likely to have specialised structures for wind dispersal. Habitat specificity and narrower niche of non-mycorrhizal plants might explain the smaller investment in specialised structures for seed dispersal.
\end{abstract}

\section{Keywords}

Diaspora syndromes, dispersal, fungi, mutualism, mycorrhiza, non-mycorrhizal plants, plant communities.

Ecology Letters (2018)

\section{INTRODUCTION}

Seed dispersal is a key ecosystem function that allows plants to occupy newly available niches, avoid competition, find suitable conditions for germination and expand their distribution range (Howe \& Smallwood 1982; Traveset et al. 2014). One of the main advantages of seed dispersal comes from allowing the next generation to escape the high mortality rates near the mother plant due to fraternal competition and high densities of specific natural enemies, for example pathogens, parasites, herbivores and seed predators (Connell 1970; Janzen 1970; Comita et al. 2014). Furthermore, the seed dispersal service helps maintaining genetic diversity by reducing the chance of inbreeding and promoting adaptation to new environments (Traveset et al. 2014). In particular, long-distance dispersal (LDD) of seed has been identified as the key process regulating the distribution of plant species and is critical in the colonisation of new territories such as islands (Arjona et al. 2017). The advantages of seed dispersal led to a selective pressure towards the specialisation of particular dispersal syndromes that is groups of morphological traits that promote the dispersal of diaspores by specific vectors to which they are specially well adapted (Hughes et al. 1994). Although there are many seed dispersal syndromes, only four can provide an effective advantage for dispersal over long distances, namely endozoochorous (ingestion by animals), epizoochorous (external adhesion to animas), anemochorous (wind) and thalassochorous (oceanic currents; Heleno \& Vargas 2015 and references therein). Although some plants can be dispersed by other mechanisms than those for which they have particular adaptations - non-standard dispersal (Vargas et al. 2012) - those with specific adaptations for LDD are more likely to disperse, and disperse to greater distances, than plants without such traits (Arjona et al. 2017). Therefore, LDD syndromes are a most valuable tool to explore the effect of selective pressures acting upon seed dispersal distances (Thomson et al. 2010; Heleno \& Vargas 2015; Arjona et al. 2017). Animaldriven seed dispersal has important advantages over abiotic vectors and, in fact, animals disperse up to 90 and $60 \%$ of plant species in tropical and temperate regions respectively (Traveset et al. 2014).

A rarely considered corollary for the concentration of specific enemies around parent plants is that suitable specific friends (mutualists), chiefly mycorrhizal fungi, are also more likely to be found near the mother plant than after dispersal to remote sites. Therefore, despite all its advantages, dispersing can also represent a cost for plants, if in this process they could escape not only from enemies but also from their mutualistic 'friends' thus leading to a trade-off that might affect recruitment possibilities (Wilkinson 1997; Wenny 2001). Mycorrhizas, that is mutualistic interactions between soil fungi and vascular plant roots, are ubiquitous mutualisms in terrestrial ecosystems (Smith \& Read 2008). In this association, the fungal partner receives carbohydrates from the plant in exchange for soil nutrients (Smith \& Read 2008), protection from pathogens (Veresoglou \& Rillig 2012) and improved access to water (Smith \& Read 2008). Mycorrhizal fungi play a fundamental role in the organisation of terrestrial ecosystems influencing plant species community composition (Klironomos et al. 2011; van der Heijden et al. 2015) and patterns of plant succession (Allen \& Allen 1988; Francis \& Read 1994). Four mycorrhizal types are currently recognised based 
on their structure and function, namely arbuscular mycorrhiza (AM, including facultative associations, c. $80 \%$ of all plant species), ectomycorrhiza (EcM, c. $2 \%$ of plants), orchid mycorrhiza (c. $9 \%$ of plants, restricted to the Orchidaceae family) and ericoid mycorrhiza (c. $1 \%$ of plants, restricted to the Ericaceae), while about $8 \%$ of all studied plant species do not form mycorrhizas (Brundrett 2009, 2017; Moora 2014; van der Heijden et al. 2015; Brundrett \& Tedersoo 2018).

Being mycorrhizal is the ancestral state for land plants and natural selection appears to generally favour the AM symbiosis over mutualism abandonment (Maherali et al. 2016). Mycorrhizal plants can be obligate, that is forming mycorrhizas in all studied situations, or facultative, that is forming mycorrhizas only in some situations (Smith \& Read 2008). In general, EcM fungi are considered ecologically obligate partners for plants while both obligate and facultative mycorrhizal host plant species are observed in AM (Moora 2014) but obligate mycorrhizal species are predominant also for AM plants (Brundrett 2009, 2017). Mycorrhizal interactions are largely generalist, but differences exist between mycorrhizal types: EcM fungi are more host-specific than AM fungi (van der Heijden et al. 2015) while ecological specificity has been found for AM fungi (Opik et al. 2009; Rodríguez-Echeverría et al. 2017).

Importantly, mycorrhizal fungi can facilitate seedling establishment by integrating emerging seedlings into extensive hyphal networks through which they can supply nutrients to the seedlings protecting them from pathogenic soil fungi (van der Heijden et al. 2015). Although currently unexplored, the LDD of obligate mycorrhizal plant species could severely diminish their probability of finding compatible fungal mutualists which are required for effective seedling establishment (Nuñez et al. 2009), although this is probably not limiting for orchids (McCormick \& Jacquemyn 2014). Microbial dispersal is assumed to be largely stochastic (Allen et al. 1989) with no direct evidence of efficient LDD (Davison et al. 2015). Possible mechanisms for the dispersal of mycorrhizal inoculum include dispersal of fungal spores via animal faeces, airborne dispersal of propagules (spores, hyphae, sclerotia), physical soil movement and the co-dispersal of seeds and fungal propagules by biotic or abiotic dispersal mechanisms (Allen et al. 1989; Gehring et al. 2002; Mangan \& Adler 2002; Peay $\&$ Bruns 2014). A rare event of long-distance co-dispersal of plant and mycorrhizal propagules has been observed in a coastal strand plant in which rhizomes containing arbuscular mycorrhizal fungi break off and disperse (Koske \& Gemma 1990). Similarly, the co-dispersal of mycorrhizal fungal spores attached to seeds has been seldom reported (Séne et al. 2017; Ramadhani et al. 2018), thus, most plants acquire mycorrhizal fungi from the environment after germination (Smith \& Read 2008). Therefore, the need to disperse seeds to suitable sites where they can encounter compatible mycorrhizal fungi could favour the co-evolution of traits to promote a non-random dispersal of seeds and fungi spores.

Regardless of the important roles in seedling recruitment described for the mutualistic interactions established between plants and seed dispersers or mycorrhizal fungi, they have seldom been explored together, likely hindering our understanding of ecosystem dynamics (Howe \& Smallwood 1982;
Rodríguez-Echeverría \& Traveset 2015; Schupp et al. 2017). Twenty years ago, Wilkinson (1997) already argued that dispersal distance and seed deposition site will largely determine the probability of finding suitable symbiotic fungi, suggesting a trade-off between seed dispersal and mycorrhizal status. This idea was sustained by the observation that non-mycorrhizal species in the British flora tended to have smaller seeds, which were considered more dispersive, while mycorrhizal species had larger and less dispersive seeds (Peat \& Fitter 1993; Wilkinson 1997). Nevertheless, such relationship has never been formally tested and therefore we are still largely ignorant on whether and how seed dispersal and mycorrhizal status can affect each other.

In this study, we aimed to explore the putative associations between mycorrhizal status and LDD syndromes. We hypothesise that plants with specialised structures for seed dispersal will be less frequent than expected among mycorrhizal plants, while plants that do not form mycorrhizal associations will be more likely to be dispersed over long distances since recruitment is not constrained by finding compatible fungal partners.

\section{MATERIAL AND METHODS}

\section{Sources of data}

We used the information on the presence and type of structures that facilitate LDD for the spermatophytes (gymnosperms and angiosperms) from the list compiled by Heleno \& Vargas (2015). This list includes a characterisation of 10792 species from 142 families of native European species included in Flora Europaea (Tutin et al. 1980). Diaspores with wings or pappus that promote dispersal by wind were considered anemochorous; those with fleshy and nutritive tissues that promote animal ingestion as endozoochorous; those with hooks or sticky substances that facilitate the external adhesion to animals as epizoochorous, and diaspores with corky tissues or air chambers that promote floatability and protection in saltwater as thalassochorous (Vargas et al. 2012; Heleno \& Vargas 2015). Species without any specialised dispersal structures relevant for LDD were classified as 'unspecialised'. This category includes plants with syndromes that only facilitate dispersal over short distances, as well as species without specific structures associated with LDD, which is independent of diaspore size (see Appendix S1 in Heleno \& Vargas (2015) for a detailed guide of syndrome categorisation).

Information on plant mycorrhizal status and type was compiled from five main sources, namely: (1) Mycoflor, a database containing information on the mycorrhizal status of 1758 plant species (Hempel et al. 2013); (2) an updated check-list of mycorrhizal occurrence among land plants (Wang \& Qiu 2006); (3) a checklist of mycorrhiza in the British flora (Harley \& Harley 1987, 1990); (4) a database of 3000 vascular plant species across the former Soviet Union (Akhmetzhanova et al. 2012); and (5) a data set of plant mycorrhizal status and type for Europe, recently compiled by Bueno et al. (2017). To minimise errors in our database, all entries were individually checked in multiple databases and their cited references. Brundrett $(2009,2017)$ estimated $5-10 \%$ of errors for mycorrhizal databases but sensitivity analyses have shown that the results obtained with these 
databases are robust even when introducing $20 \%$ of random errors (Bueno et al. 2017; Gerz et al. 2018).

We considered three main mycorrhizal statuses: obligate mycorrhizal, facultative mycorrhizal and non-mycorrhizal plants (Smith \& Read 2008). A species was classified as obligate when it was reported as mycorrhizal in all studies/databases; facultative status was assigned when the same species was classified as both AM and NM with more than one reference for each status; and species were classified as non-mycorrhizal when none of the studies found any mycorrhizal association (Smith \& Read 2008; Hempel et al. 2013; Moora 2014). These three categories only indicate observed colonisation status but do not contain information about functionality. It should be noted that reports of colonisation status in facultative mycorrhizal plants based on the occurrence of internal hyphae and/or vesicles, but without mention to arbuscules and/or coils, are especially in need of critical scrutiny, as Brundrett (2017) considers these cases as very unlikely functional.

The obligate mycorrhizal category includes arbuscular mycorrhiza (AM), ectomycorrhiza (EcM), orchid mycorrhizas (ORM) and ericoid mycorrhiza (ERM; Smith \& Read 2008; Moora 2014), while facultative associations are described only in AM (Brundrett 2009; Hempel et al. 2013; Moora 2014). About $4 \%$ of the plant species had more than one type of mycorrhiza but numbers in the different dual mycorrhiza combinations were low, and thus, they were not used in the analysis. Plant species reported as having EcM and another mycorrhizal type (EcM-AM, EcM-ericoid) were classified as EcM to distinguish species that were potentially capable of forming EcM symbiosis from those that could not (Maherali et al. 2016).

Species names were standardised according to The Plant List 1.1 using the taxonstand $1.7 \mathrm{R}$ package (Cayuela et al. 2012). Higher taxonomic membership was corrected to the APG IV (Angiosperm phylogeny group, IV, 2016).

We obtained a final database with information on mycorrhizal status and LDD syndromes for 1960 plant species from 685 genera and 124 families (see Appendix S1). Our database contains c. $18 \%$ of the spermatophytes (gymnosperms and angiosperms) of the flora of Europe, and we did not detect any bias preventing the use of these species for the analyses (see Appendix S2). The most represented families in our study are the most common in the European flora, namely Compositae (12\% of the species), Rosaceae (6\%), Cyperaceae $(6 \%)$, Fabaceae $(5 \%)$, Poaceae $(4 \%)$ and Orchidaceae $(3 \%)$, while $29 \%$ of the families were represented by a single species.

\section{Statistical analyses}

We looked for univariate relationships between mycorrhizal status or mycorrhizal types and LDD syndromes using loglinear analysis with maximum likelihood chi-squared and post hoc Freeman-Tukey deviation tests (Legendre \& Legendre 1988). Bonferroni corrections were used to reduce the chance of spurious false positives. All analyses were performed using the statistical software $\mathrm{R}$ ( $\mathrm{R}$ Development Core Team 2017).

Mycorrhizal status (obligatory, facultative and non-mycorrhizal) and mycorrhizal types (AM, EcM, ORM and ERM) were tested first against the presence or absence of LDD syndromes and subsequently against the proportion of different seed dispersal syndromes (anemochorous, epizoochorous, endozoochorous, thalassochorous and unspecialised). The analyses evaluating the presence of LDD syndromes across plants with different mycorrhizal types did not include facultative associations and therefore were performed with a subset of the data $(n=1566$ species). To account for the phylogenetic relatedness of species, all analyses were performed using a phylogenetic species richness index (Helmus et al. 2007) that corrects simple taxonomic diversity by discounting species phylogenetic relatedness (Helmus et al. 2007). Phylogenetic species richness was calculated for each combination of mycorrhizal and dispersal categories described above using the $\mathrm{R}$ package 'picante' (Kembel et al. 2010) and used in the contingency tables as in Pyšek et al. (2011) and Hempel et al. (2013; see Appendix S3 for a detailed description of the phylogenetic correction methods).

The phylogenetic correction based on the phylogenetic species richness index required the reconstruction of a phylogenetic tree of the 1960 plant species assembled using the 'S.PhyloMaker' function implemented for R (see Supplementary Material; Qian \& Jin 2016) and constructed based on PhytoPhylo tree (Qian \& Jin 2016), a comprehensive specieslevel phylogeny of vascular plants generated by Zanne et al. (2014) and updated by Qian \& Jin (2016). The phylogenetic tree obtained for the final compiled database had 1952 tip labels and 1682 internal nodes (Fig. 1).

\section{RESULTS}

The proportion of different mycorrhizal status and LDD syndromes in our database $(n=1960)$ followed those of global and European databases respectively (Smith \& Read 2008; Heleno \& Vargas 2015). Most plants in our database formed mycorrhizas $(82 \%)$, counting $1218(62 \%)$ species recorded as obligate mycorrhizal (OM) and $395(20 \%)$ species as facultative mycorrhizal (FM). Only 348 species $(18 \%)$ were classified as non-mycorrhizal (NM). Within the obligate mycorrhizal species, $81 \%(n=982)$ were arbuscular mycorrhizal, $11 \%$ $(n=137)$ ectomycorrhizal, 5\% $(n=59)$ orchid mycorrhizal and $3 \%(n=39)$ ericoid mycorrhizal. As in the database assembled by Heleno \& Vargas (2015), the majority of species had unspecialised diaspores (c. 60\%; see Appendix S2), while anemochorous traits were the most common of LDD syndromes in the remaining species $(19 \%)$, followed by epizoochorous $(8 \%)$, endozoochorous $(8 \%)$ and thalassochorous (4\%; see Appendix 2). The phylogenetic tree showed the widespread distribution of arbuscular mycorrhizal species, being present in $c .86 \%$ of all families and in $c .80 \%$ of the genera (Fig. 1). Likewise, the presence and type of diaspore adaptations for long-distance dispersal are largely scattered across the whole phylogenetic tree (Fig. 1).

According to the phylogenetically corrected log-linear analysis (see Appendix S4 for detailed results), we found that the proportion of obligate mycorrhizal plants with LDD syndromes is higher than expected (Fig. 2a, Table 1, Table S3.1). Facultative mycorrhizal species and non-mycorrhizal plants showed the opposite pattern with only 32 and $18 \%$ of the 


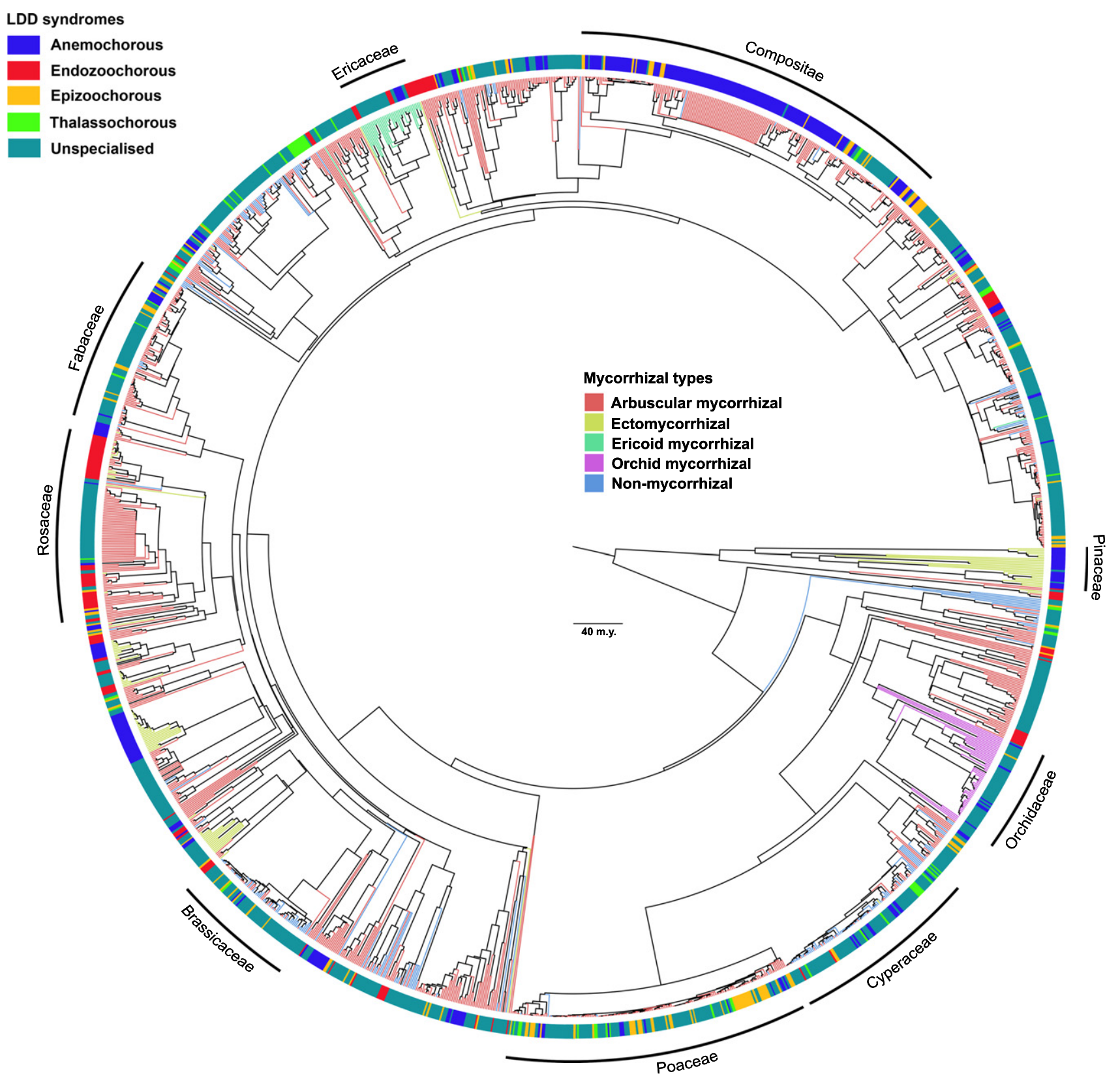

Figure 1 A time-calibrated phylogeny for the 1960 plant species used in this study. Tip colour denotes the mycorrhizal type: arbuscular mycorrhizal (red), ectomycorrhizal (light green), ericoid mycorrhizal (green), orchid mycorrhizal (purple) and non-mycorrhizal (blue). Colour of tip labels indicates the longdistance dispersal (LDD) syndrome: anemochorous (blue), endozoochorous (red), epizoochorous (orange), thalassochorous (green) and unspecialised diaspores (blue-green). Important families in the data set are indicated in the figure. A 40-million-year-long reference bar illustrates the timescale of the phylogeny.

species bearing structures for LDD, which is significantly lower than the expected 40\% (Fig. 2a, Table 1; Table S3.1).

When considering the different LDD syndromes, the analysis revealed a significantly higher percentage of species with specializations for wind dispersal (anemochorous) and for animal ingestion of fleshy fruits (endozoochorous) within obligate mycorrhizal species (Fig. 2b, Table 1, Table 3.2). The percentage of thalassochorous diaspores was significantly lower than expected within obligate mycorrhizal species. For plants with a facultative mycorrhizal association, anemochorous diaspores were significantly less common than expected (Fig. 2b, Table 1, Table S3.2). Anemochorous, endozoochorous and epizoochorous dispersal modes were under-represented among non-mycorrhizal plants (Fig. 2b, Table S3.2). Thalassochorous diaspores were the most commonly observed syndrome in non-mycorrhizal plants, although significant differences were not detected.

The phylogenetically corrected log-linear analysis for the presence of LDD syndromes in plants with different mycorrhizal types (AM, EcM, ORM, ERM and non-mycorrhizal) 
(a)

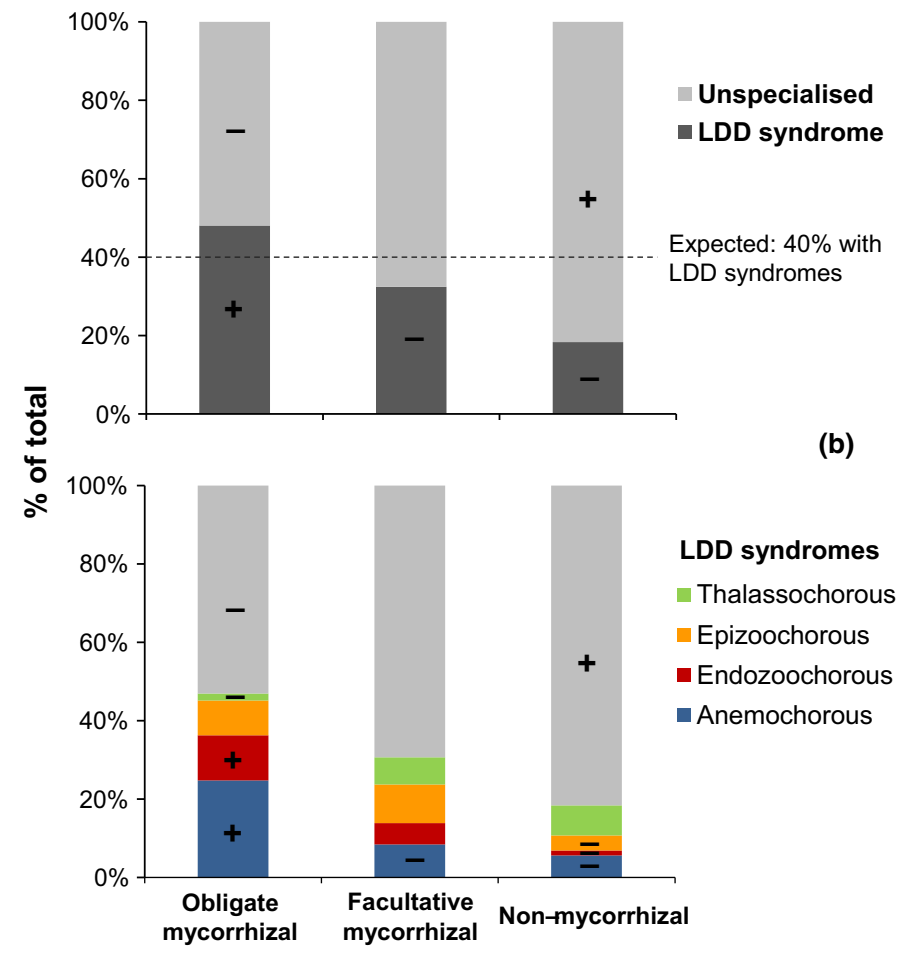

Figure 2 (a) Relative proportions (\% of total) of specialised structures for long-distance seed dispersal (LDD syndromes) in plants with different mycorrhizal statuses: obligate (OM), facultative (FM) and nonmycorrhizal plant species. (b) Relative proportion of LDD syndromes (anemochorous, endozoochorous, epizoochorous and thalassochorous) or unspecialised diaspores in plants with different mycorrhizal status: obligate, facultative and non-mycorrhizal plant species. Plus (+) signs indicate significantly higher percentages, and minus signs $(-)$ indicate significantly lower percentages than expected by the log-linear model (Freeman-Tukey deviation test, $P<0.001$ ). The expected proportion of unspecialised/specialised dispersal structures $(60 / 40 \%)$ is marked with a dashed line.

Table 1 Results of phylogenetically corrected log-linear analyses examining the relationship between mycorrhizal status/type and dispersal specialisation in a list of 1960 plant species from the flora of Europe. Mycorrhizal status (obligate, facultative and non-mycorrhizal) and mycorrhizal types (arbuscular mycorrhizal - AM, ectomycorrhizal - EcM, ericoid mycorrhizal - ERM and orchid mycorrhizal - ORM) were tested either against the presence or absence of long-distance dispersal (LDD) syndrome or LDD syndrome type including no-syndrome

\begin{tabular}{|c|c|c|c|}
\hline & & \multicolumn{2}{|c|}{ Long-distance dispersal syndrome } \\
\hline & & $\begin{array}{l}\text { Syndrome/ } \\
\text { no-syndrome }\end{array}$ & $\begin{array}{l}\text { Anemochorous, } \\
\text { epizoochorous, } \\
\text { endozoochorous, } \\
\text { thalassochorous } \\
\text { or no-syndrome }\end{array}$ \\
\hline \multicolumn{4}{|c|}{ Mycorrhizal } \\
\hline Status & $\begin{array}{l}\text { Obligate, } \\
\text { facultative and } \\
\text { non-mycorrhizal }\end{array}$ & $\begin{array}{l}N=1960, \mathrm{df}=2 \\
\chi^{2}=48.51 \\
P<0.001\end{array}$ & $\begin{array}{l}N=1960, \mathrm{df}=8 \\
\chi^{2}=89.95 \\
P<0.001\end{array}$ \\
\hline Type & $\begin{array}{l}\text { AM, EcM, } \\
\text { ERM and } \\
\text { ORM }\end{array}$ & $\begin{array}{l}N=1566, \mathrm{df}=4 \\
\chi^{2}=87.56 \\
P<0.001\end{array}$ & $\begin{array}{l}N=1566, \mathrm{df}=9 \\
\chi^{2}=131.22, \\
P<0.001\end{array}$ \\
\hline
\end{tabular}

showed that LDD syndromes were more frequent than expected in plants forming ectomycorrhizal associations (Fig. 3a, Table 1; Table S4.1). The percentage of species with specialised LDD syndromes did not differ from the expected proportion for plants with arbuscular, orchid and ericoid mycorrhizas (Fig. 3a, Table 1; Table S4.1). A significantly higher proportion of non-mycorrhizal plants, however, lacked specialised LDD structures. The analysis considering all the syndromes showed a significantly higher proportion of species with anemochorous diaspores for ectomycorrhizal plants $(c$. $51 \%$ of EcM species had structures related to anemochorous dispersal; Fig. 3b; see Table S4.2). Epizoochorous and thalassocorous diaspores were absent in EcM, ERM and ORM plants. In EcM species, unspecialised diaspores occurred in a significantly lower proportion than expected (c. $18 \%$ vs. expected $60 \%$ ). Significant deviations from the expected frequencies were also found for anemochorous, endozoochorous and epizoochorous dispersal syndromes in non-mycorrhizal plants, with lower values than expected.

\section{DISCUSSION}

Seeds represent a key stage in the life of plants, during which they can move to new locations and, by doing so, escape from enemies and intraspecific competition. However, most plants establish symbiotic associations with mycorrhizal fungi soon after germination, which are vital for seedling emergence and recruitment success. Therefore, plants might be trapped in a trade-off defined by the need of escaping from their 'enemies' without losing their 'friends' in the process. While most plants are typically dispersed over short distances, that is $1-2$ canopies of the parent plant's, where they can still access local symbionts (Dickie \& Reich 2005), many species have developed special adaptations to promote the LDD of their seeds (Nathan et al. 2008). Thus, plants appear to have two alternative strategies: (1) to disperse only over short distances to secure a supply of symbionts for their seedlings while coping with local enemies and competitors and (2) to disperse over long distances to escape from their enemies and competitors, but lose the acquainted symbionts in the process. Although this potential trade-off was hinted c. 20 years ago (Wilkinson 1997), it has never been tested. Following Wilkinson's idea, our hypothesis was that obligatory mycorrhizal plants will be less likely to bear LDD syndromes since the probability of finding suitable mycorrhizal partners would decrease with distance from the mother plant (Fig. 4).

Contrary to our expectations, we found that having specialised structures for dispersal is significantly more frequent in obligate mycorrhizal plants than in non-mycorrhizal plants (48 vs. 18\%). Particularly, anemochorous and endozoochorous diaspores are more frequent than expected in obligate mycorrhizal plants. While many plant species developed specialisations that facilitate dispersal by wind (i.e. anemochorous diaspores), animal-driven seed dispersal by endozoochory has important advantages over abiotic vectors, chiefly in that larger seeds can be transported for generally longer distances and seeds can be delivered into particularly suitable recruitment sites (Traveset et al. 2014 and references therein). 


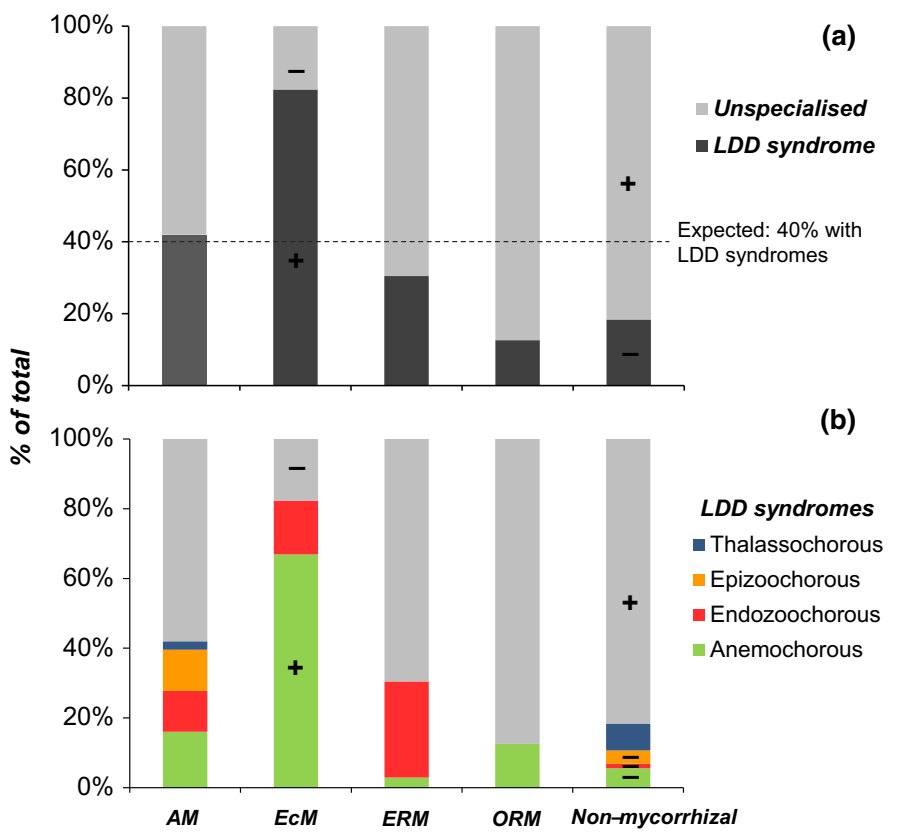

Figure 3 (a) Relative proportions (\% of total) of specialised structures for long-distance seed dispersal (LDD syndromes) in plants with different mycorrhizal types: arbuscular mycorrhiza (AM), ectomycorrhiza (EcM), ericoid mycorrhiza (ERM), orchid mycorrhiza (ORM) or non-mycorrhizal. (b) Relative proportion of LDD syndromes (anemochorous, endozoochorous, epizoochorous and thalassochorous) or unspecialised diaspores in plants with different mycorrhizal types: arbuscular mycorrhiza (AM), ectomycorrhiza (EcM), ericoid mycorrhiza $($ ERM), orchid mycorrhiza (ORM) or non-mycorrhizal. Plus $(+)$ signs indicate significantly higher percentages, and minus signs $(-)$ indicate significantly lower percentages than expected by the log-linear model (Freeman-Tukey deviation test, $P<0.001)$. The expected proportion of unspecialised/specialised dispersal structures $(60 / 40 \%)$ is marked with a dashed line.
Thus, this study suggests that finding mycorrhizal partners is not an important limitation for plant establishment, likely due to a low symbiotic specificity, especially for arbuscular mycorrhizas (van der Heijden et al. 2015), and to the broad range distribution of fungi (Tedersoo et al. 2014; Davison et al. 2015; Vincenot \& Selosse 2017). Indeed, 93\% of AM fungal taxa occur in multiple continents and 34\% have been found in all six continents (Davison et al. 2015). Although the LDD of mycorrhizal fungi remains poorly understood, there is some evidence for successful dispersal of AM fungal spores mainly by animal vectors and soil movement, but also by wind in arid regions (Warner et al. 1987; Allen \& Allen 1988). EcM fungal species forming epigeous sporocarps are readily dispersed by wind to considerable distances while species with hypogeous fruitbodies are mainly dispersed by mycophages (Peay \& Bruns 2014; Vincenot \& Selosse 2017).

When analysed in detail, we found that the positive association between obligate mycorrhizas and LDD syndromes is mainly driven by EcM plant species with anemochorous diaspores. Indeed, only $20 \%$ of all EcM species have unspecialised diaspores, compared to $60 \%$ for the whole database or the European flora. Interestingly, anemochorous diaspores were three times more frequent than expected among EcM plants. Finding a compatible fungal partner might be more critical for EcM plants than for AM plants since ectomycorrhizal fungi tend to have a higher specificity (Bahram et al. 2014; Tedersoo et al. 2014). Actually, the lack of compatible EcM fungi can delay the expansion of forests because compatible fungal inocula decreases greatly with distance from the forest edge (e.g. Dickie \& Reich 2005). Also, a lack of EcM fungi has been reported to prevent the spread of alien plants in introduced areas highlighting the specificity of this symbiosis for some species (e.g. Nuñez et al. 2009). It might be also noted that EcM occur mostly in trees and shrubs (van der Heijden et al. 2015) and that tall plant species have a greater
Original hypothesis
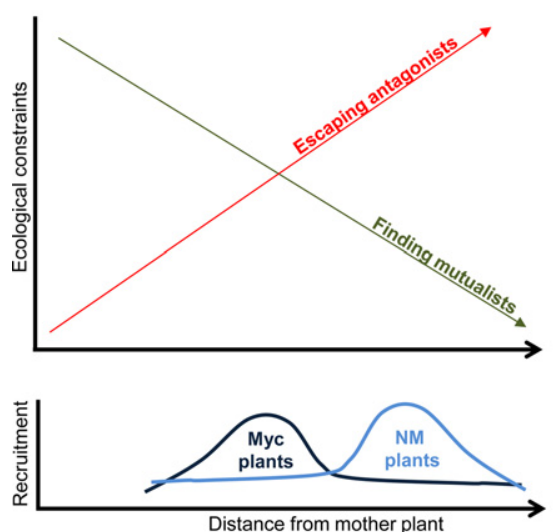

Proposed model
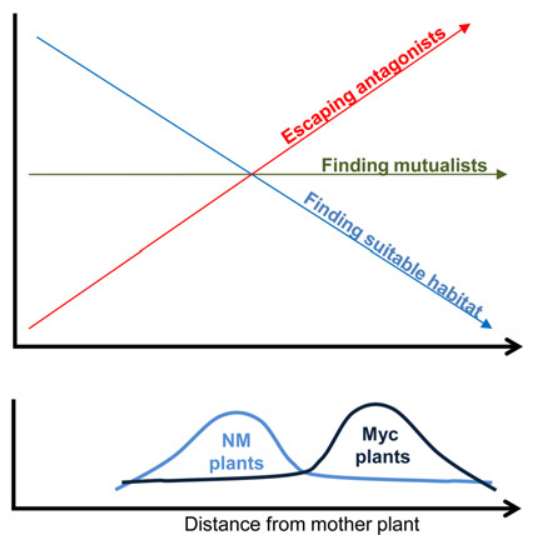

Figure 4 Seed dispersal allows plants to escape natural enemies and intraspecific competition near the mother plant. Our original hypothesis was that the long-distance dispersal of obligate mycorrhizal plant species could severely decrease their probability of finding compatible fungal mutualists required for seedling establishment. In this situation, mycorrhizal plants would have increased fitness if they recruit near the mother plant were they can find mutualistic partners while non-mycorrhizal plants would have increased fitness away from antagonists. Alternatively, our results suggest that finding compatible mutualists is not an important constraint for the recruitment of mycorrhizal species, likely due to the low specificity of the symbiosis and the ubiquity of mycorrhizal fungi. However, investing in long-distance dispersal structures might not be so beneficial to non-mycorrhizal plants given their high habitat specificity and the lower probability of finding suitable habitats away from the mother plant. 
probability of having seed dispersal structures and disperse over longer distances (Thomson et al. 2018). Thus, we propose that the association between EcM and LDD syndromes towards wind dispersal might be advantageous for the expansion of EcM plants since many of their mycorrhizal partners can be dispersed to considerable distances by wind.

Interestingly, epizoochorous and thalassochorous diaspores did not occur in EcM or ERM. Epizoochorous plants tend to be herbaceous with many representative species in arbuscular mycorrhizal families such as Apiaceae and Compositae (Sorensen 1986), while thalassochorous plants from coastal and wetland habitats are predominantly AM or non-mycorrhizal (Brundrett 2009). Interestingly, endozoochorous diaspores are very common among ERM plants. Further research including other functional and ecological traits could be useful to fully understand the observed differences. On the other hand, orchids (ORM) only presented unspecialised or anemochorous diaspores which are tiny and, thus, are readily dispersed by wind (McCormick \& Jacquemyn 2014).

Specialised structures for dispersal, particularly those related to dispersal by wind, are less frequent in facultative mycorrhizal plants than in obligate mycorrhizal plants (32 vs. $48 \%$ ). Other studies have also found differences in realised niches, geographical amplitude, functional traits and distribution of obligate and facultative plants in Europe (Hempel et al. 2013; Bueno et al. 2017; Gerz et al. 2018). However, the ultimate drivers of such differences are still poorly understood. Further research that incorporates rigorous evaluation of the mycorrhizal status of more plant species is still needed.

Surprisingly, the largest deviation from the expected proportion of LDD structures was found in non-mycorrhizal species, where only $18 \%$ of plant species have specialised dispersal modes while the expected proportion was $40 \%$. The absence of mycorrhizas is considered an adaptation by plants to environments with extreme nutrient availability (Lambers \& Teste 2013). In this sense, non-mycorrhizal plants can be considered habitat specialists since they are either short-lived weedy species that grow in disturbed habitats or plants adapted to Pimpoverished soils with P-mining strategies based on specialised root structures and/or carboxylate exudation (Miller 2005; Brundrett 2009; Lambers \& Teste 2013). Non-mycorrhizal plants have smaller realised niches (Gerz et al. 2018) and occupy fewer habitats than mycorrhizal plants (Hempel et al. 2013). In the European flora, non-mycorrhizal species are typically annuals, herbaceous and stress tolerant (Hempel et al. $2013)$ that produce small seeds $(<0.1 \mathrm{mg}$; Peat \& Fitter 1993). The cost of producing dispersal structures for small seeds may be disproportionately high, thus, making unlikely the presence of specialised dispersal structures (Mary et al. 1990). Obviously, the absence of specialised structures related to LDD does not preclude lightweight seeds from being dispersed by various mechanisms (e.g. by wind or internally and externally by animals); however, they will likely disperse less often and over lower mean distances than seeds with specialised LDD structures (Heleno et al. 2011; Costa et al. 2014; Traveset et al. 2014; Arjona et al. 2017). We propose that the absence of LDD syndromes is driven by the narrower niche and high habitat specificity of non-mycorrhizal species. Due to their habitat restriction and characteristic life traits, long-distance dispersal of non-mycorrhizal plants might reduce fitness by decreasing the probability of finding a suitable site to establish. Databases that integrate the mycorrhizal status with other life traits are needed to allow a robust analysis of putative links between plant traits, niche width and habitat specificity to gain a better understanding of the biology of non-mycorrhizal plants.

In a nutshell, our study suggests that strategies for LDD of seed are not constrained by the need of finding suitable mycorrhizal fungi, probably due to the low specificity of these mutualistic symbioses (Fig. 4). On the contrary, we found a positive association between plants that form EcM and diaspores with adaptations that favour dispersal by wind, which is also the main dispersal vector for their mycorrhizal partners. The opposite was found for non-mycorrhizal plants where a high proportion of species have diaspores without specialised LDD structures. We propose that the high habitat specialisation of non-mycorrhizal plants is associated with a set of plant traits that include the lack of specialised LDD syndromes. Although rarely considered together, we show that there is a high potential for mutual constraints between plant mycorrhizal and seed dispersal strategies during the evolution of plants. Further studies using data from other bioclimatic regions are needed to assess the generality of the patterns found here for temperate and Mediterranean areas. The analysis of tropical floras might be especially interesting since they have different proportions of LDD syndromes and mycorrhizal types than the European flora (Heleno \& Vargas 2015; Rodríguez-Echeverría et al. 2017; Brundrett \& Tedersoo 2018). Nevertheless, the balance between escaping from enemies, and finding suitable partners and habitats is likely ubiquitous and therefore a trade-off between seed dispersal and plant mycorrhizal strategies may be expected in other parts of the globe.

\section{ACKNOWLEDGEMENTS}

M.C., R.H. and S.R-E. were supported by the Portuguese Foundation for Science and Technology - FCT (Grants SFRH/BD/96050/2013, IF/00441/2013 and IF/00462/2013, respectively). The authors want to thank Ruben Torices and John Davison for his help in the phylogenetic analysis and to João Crisóstomo for his help with Figure 1. We thank the associate editors and three anonymous referees for their helpful comments that allowed us to improve the overall quality of the manuscript.

\section{AUTHORSHIP}

MC, RH and SR-E designed the research; MC, PV and RH collected the data; MC and SR-E analysed the data; MC wrote the first draft of the manuscript and all authors contributed substantially to the revisions.

\section{REFERENCES}

Akhmetzhanova, A.A., Soudzilovskaia, N.A., Onipchenko, V.G., Cornwell, W.K., Agafonov, V.A., Selivanov, I.A. et al. (2012). A rediscovered treasure: mycorrhizal intensity database for 3000 vascular plant species across the former Soviet Union. Ecology, 93, 689-690. 
Allen, E.B. \& Allen, M.F. (1988). The mediation of competition by mycorrhizae in successional and patchy environments. In Perspectives on Plant Competition. (eds Grace, J.B., Tilman, G.D.). Academic Press, New York, NY, pp. 367-389.

Allen, M.F., Hipps, L.E. \& Wooldridge, G.L. (1989). Wind dispersal and subsequent establishment of VA mycorrhizal fungi across a successional arid landscape. Landscape Ecol., 2, 165-171.

Angiosperm phylogeny group (2016). An update of the Angiosperm Phylogeny Group classification for the orders and families of flowering plants: APG IV. Bot. J. Linn. Soc., 181, 1-20.

Arjona, Y., Nogales, M., Heleno, R. \& Vargas, P. (2017). Long-distance dispersal syndromes matter: diaspore-trait effect on shaping plant distribution across the Canary Islands. Ecography. https:// doi.org/10.1111/ecog.02624.

Bahram, M., Harend, H. \& Tedersoo, L. (2014). Network perspectives of ectomycorrhizal associations. Fungal Ecol., 7, 70-77.

Brundrett, M.C. (2009). Mycorrhizal associations and other means of nutrition of vascular plants: understanding the global diversity of host plants by resolving conflicting information and developing reliable means of diagnosis. Plant Soil, 320, 37-77.

Brundrett, M.C. (2017). Global diversity and importance of mycorrhizal and nonmycorrhizal plants. In Biogeography of Mycorrhizal Symbiosis. (ed Tedersoo, L.). Springer, Cham, pp. 533-556.

Brundrett, M.C. \& Tedersoo, L. (2018). Evolutionary history of mycorrhizal symbioses and global host plant diversity. New Phytol. https://doi.org/10.1111/nph.14976.

Bueno, C.G., Moora, M., Gerz, M., Davison, J., Öpik, M., Pärtel, M. et al. (2017). Plant mycorrhizal status, but not type, shifts with latitude and elevation in Europe. Glob. Ecol. Biogeog., 26, 690-699.

Cayuela, L., Granzow-de la Cerda, Í., Albuquerque, F.S. \& Golicher, D.J. (2012). Taxonstand: an $\mathrm{R}$ package for species names standardisation in vegetation databases. Methods Ecol. Evol., 3, 1078-1083.

Comita, L.S., Queenborough, S.A., Murphy, S.J., Eck, J.L., Xu, K., Krishnadas, M. et al. (2014). Testing predictions of the Janzen-Connell hypothesis: a meta-analysis of experimental evidence for distance- and density-dependent seed and seedling survival. J. Ecol., 102, 845-856.

Connell, J.H. (1970). On the role of natural enemies in preventing competitive exclusion in some marine animals and in rain forest trees. In Dynamics of Population. (eds Boer, P.J.D., Gradwell, G.R.). Pudoc, Wageningen, the Netherlands.

Costa, J.M., Ramos, J.A., da Silva, L.P., Timoteo, S., Araújo, P.M., Felgueiras, M.S. et al. (2014). Endozoochory largely outweighs epizoochory in migrating passerines. J. Avian Biol., 45, 59-64.

Davison, J., Moora, M., Öpik, M., Adholeya, A., Ainsaar, L., Bâ, A. et al. (2015). Global assessment of arbuscular mycorrhizal fungus diversity reveals very low endemism. Science, 349, 970-973.

Dickie, I.A. \& Reich, P.B. (2005). Ectomycorrhizal fungal communities at forest edges. J. Ecol., 93, 244-255.

Francis, R. \& Read, D.J. (1994). The contributions of mycorrhiza fungi to the determination of plant community structure. Plant Soil, $159,11-25$.

Gehring, C.A., Wolf, J.E. \& Theimer, T.C. (2002). Terrestrial vertebrates promote arbuscular mycorrhizal fungal diversity and inoculum potential in a rain forest soil. Ecol. Lett., 5, 540-548.

Gerz, M., Bueno, C.G., Ozinga, W.A., Zoberl, M. \& Moora, M. (2018). Niche differentiation and expansion of plant species are associated with mycorrhizal symbiosis. J. Ecol., 106, 254-264.

Harley, J.L. \& Harley, E.L. (1987). A check-list of mycorrhiza in the British flora. New Phytol., 105, 1-102.

Harley, J.L. \& Harley, E.L. (1990). A check-list of mycorrhiza in the British Flora - Second Addenda and Errata. New Phytol., 115, 699711.

van der Heijden, M.G.A., Martin, F.M., Selosse, M.A. \& Sanders, I.R. (2015). Mycorrhizal ecology and evolution: the past, the present, and the future. New Phytol., 205, 1406-1423.

Heleno, R.H. \& Vargas, P. (2015). How do islands become green? Glob. Ecol. Biogeogr., 24, 518-526.
Heleno, R.H., Ross, G., Everard, A.M.Y., Memmott, J. \& Ramos, J.A. (2011). The role of avian "seed predators" as seed dispersers. Ibis (Lond. 1859), 153, 199-203.

Helmus, M.R., Bland, T.J., Williams, C.K. \& Ives, A.R. (2007). Phylogenetic measures of biodiversity. Am. Nat., 169, E68-E83.

Hempel, S., Götzenberger, L., Kühn, I., Michalski, S.G., Rillig, M.C., Zobel, M. et al. (2013). Mycorrhizas in the Central European flora: relationships with plant life history traits and ecology. Ecology, 94, 1389-1399.

Howe, H.F. \& Smallwood, J. (1982). Ecology of seed dispersal. Аnпи. Rev. Ecol. Syst., 13, 201-228.

Hughes, L., Dunlop, M., French, K., Leishman, M.R., Rodgerson, L., Westoby, M. et al. (1994). Predicting dispersal spectra: a minimal set of hypotheses based on plant attributes. J. Ecol., 82, 933-950.

Janzen, D.H. (1970). Herbivores and the number of tree species in tropical forests. Am. Nat., 104, 501-528.

Kembel, S.W., Cowan, P.D., Helmus, M.R., Cornwell, W.K., Morlon, H., Ackerly, D.D. et al. (2010). Picante: R tools for integrating phylogenies and ecology. Bioinformatics, 26, 1463-1464.

Klironomos, J., Zobel, M., Tibbett, M., Stock, W.D., Rillig, M.C., Parrent, J.L. et al. (2011). Forces that structure plant communities: quantifying the importance of the mycorrhizal symbiosis. New Phytol., 189, 366-370.

Koske, R.E. \& Gemma, J. (1990). VA mycorrhizae in strand of Hawaii: evidence for long-distance codispersal of plants and fungi. Am. J. Bot., 77, 466-474.

Lambers, H. \& Teste, F.P. (2013). Interactions between arbuscular mycorrhizal and non-mycorrhizal plants: do non-mycorrhizal species at both extremes of nutrient availability play the same game? Plant, Cell Environ., 36, 1911-1915.

Legendre, P. \& Legendre, L. (1988). Numerical Ecology: Developments in Environmental Modelling, 3rd edn. Elsevier, Amsterdam, the Netherland, pp. 231-235.

Maherali, H., Oberle, B., Stevens, P.F., Cornwell, W.K. \& McGlinn, D.J. (2016). Mutualism persistence and abandonment during the evolution of the mycorrhizal symbiosis. Am. Nat., 188, 113-125.

Mangan, S.A. \& Adler, G.H. (2002). Seasonal dispersal of arbuscular mycorrhizal fungi by spiny rats in a neotropical forest. Oecologia, 131, 587-597.

Mary, F., Rice, B.L. \& Westoby, M. (1990). Seed dispersal spectra: a comparison of temperate plant communities. J. Veg. Sci., 1, 547-562.

McCormick, M.K. \& Jacquemyn, H. (2014). What constrains the distribution of orchid populations? New Phytol., 202, 392-400.

Miller, R.M. (2005). The nonmycorrhizal root: a strategy for survival in nutrient-impoverished soils. New Phytol., 165, 655-658.

Moora, M. (2014). Mycorrhizal traits and plant communities: perspectives for integration. J. Veg. Sci., 25, 1126-1132.

Nathan, R., Schurr, F.M., Spiegel, O., Steinitz, O., Trakhtenbrot, A. \& Tsoar, A. (2008). Mechanisms of long-distance seed dispersal. Trends Ecol. Evol., 23, 638-647.

Nuñez, M.A., Horton, T.R. \& Simberloff, D. (2009). Lack of belowground mutualisms hinders Pinaceae invasions. Ecology, 90, 2352-2359.

Opik, M., Metsis, M., Daniell, T.J., Zobel, M. \& Moora, M. (2009). Large-scale parallel 454 sequencing reveals host ecological group specificity of arbuscular mycorrhizal fungi in a boreonemoral forest. New Phytol., 184, 424-437.

Peat, H.J. \& Fitter, A.H. (1993). The distribution of arbuscular mycorrhizas in the British Flora. New Phytol., 125, 845-854.

Peay, K.G. \& Bruns, T.D. (2014). Spore dispersal of basidiomycete fungi at the landscape scale is driven by stochastic and deterministic processes and generates variability in plant-fungal interactions. New Phytol., 204, 180-191.

Pyšek, P., Jarošík, V., Chytrý, M., Danihelka, J., Kühn, I., Pergl, J. et al. (2011). Successful invaders co-opt pollinators of native flora and accumulate insect pollinators with increasing residence time. Ecol. Monog., 81, 277-293. 
Qian, H. \& Jin, Y. (2016). An updated megaphylogeny of plants, a tool for generating plant phylogenies and an analysis of phylogenetic community structure. J. Plant Ecol., 9, 233-239.

R Development Core Team (2017). R: A Language and Environment for Statistical Computing. R Foundation for Statistical Computing, Vienna, Austria.

Ramadhani, I., Sukarno, N. \& Listiyowati, S. (2018). Basidiospores attach to the seed of Shorea leprosula in lowland tropical dipterocarp forest and form functional ectomycorrhiza on seed germination. Mycorrhiza, 28, 85-92.

Rodríguez-Echeverría, S. \& Traveset, A. (2015). Putative linkages between below- and aboveground mutualisms during alien plant invasions. $A o B$ Plants, 7, plv062.

Rodríguez-Echeverría, S., Teixeira, H., Correia, M., Timóteo, S., Heleno, R., Öpik, M. et al. (2017). Arbuscular mycorrhizal fungi communities from tropical Africa reveal strong ecological structure. New Phytol., 213, 380-390.

Schupp, E.W., Jordano, P. \& Gómez, J.M. (2017). A general framework for effectiveness concepts in mutualisms. Ecol. Lett., 20, $577-590$.

Séne, S., Selosse, M., Forget, M. \& Lambourdière, J. (2017). A pantropically introduced tree is followed by specific ectomycorrhizal symbionts due to pseudo-vertical transmission. ISME J., in press (accepted).

Smith, S.E. \& Read, D.J. (2008). Mycorrhizal Symbiosis, 3rd edn. Academic Press, New York, NY.

Sorensen, A.E. (1986). Seed dispersal by adhesion. Annu. Rev. Ecol. Syst., 17, 443-463.

Tedersoo, L., Bahram, M., Põlme, S., Kõljalg, U., Yorou, N.S., Wijesundera, R. et al. (2014). Global diversity and geography of soil fungi. Science, 346, 1052-1053.

Thomson, F.J., Moles, A.T., Auld, T.D., Ramp, D., Ren, S. \& Kingsford, R.T. (2010). Chasing the unknown: predicting seed dispersal mechanisms from plant traits. J. Ecol., 98, 1310-1318.

Thomson, F.J., Letten, A.D., Tamme, R., Edwards, W. \& Moles, A.T. (2018). Can dispersal investment explain why tall plant species achieve longer dispersal distances than short plant species? New Phytol., 217, 407-415.

Traveset, A., Heleno, R. \& Nogales, M. (2014). The ecology of seed dispersal. In Seeds: The Ecology of Regeneration in Plant
Communities. (ed Gallagher, R.S.). CAB International, Oxfordshire, UK, pp. 62-93.

Tutin, T.G., Heywood, V.H., Burges, N.A. \& Moore, D.M. (1980). Flora Europaea. Cambridge University Press, Cambridge, UK.

Vargas, P., Heleno, R., Traveset, A. \& Nogales, M. (2012). Colonization of the Galápagos Islands by plants with no specific syndromes for longdistance dispersal: a new perspective. Ecography, 35, 33-43.

Veresoglou, S.D. \& Rillig, M.C. (2012). Suppression of fungal and nematode plant pathogens through arbuscular mycorrhizal fungi. Biol. Lett., 8, 214-217.

Vincenot, L. \& Selosse, M.-A. (2017). Population biology and ecology of ectomycorrhizal fungi. In Biogeography of Mycorrhizal Symbiosis. (ed Tedersoo, L.). Springer, Cham, pp. 39-59.

Wang, B. \& Qiu, Y.L. (2006). Phylogenetic distribution and evolution of mycorrhizas in land plants. Mycorrhiza, 16, 299-363.

Warner, N.J., Allen, M.F. \& Macmahon, J.A. (1987). Dispersal agents of vesicular-arbuscular mycorrhizal fungi in a disturbed arid ecosystem. Mycologia, 79, 721-730.

Wenny, D.G. (2001). Advantages of seed dispersal: A re-evaluation of directed dispersal. Evol. Ecol. Res., 3, 51.

Wilkinson, D.M. (1997). The role of seed dispersal in the evolution of mycorrhizae. Oikos, 78, 394-396.

Zanne, A.E., Tank, D.C., Cornwell, W.K., Eastman, J.M., Smith, S.A., FitzJohn, R.G. et al. (2014). Three keys to the radiation of angiosperms into freezing environments. Nature, 506, 89-92.

\section{SUPPORTING INFORMATION}

Additional Supporting Information may be found online in the supporting information tab for this article.

Editor, Marc-André Selosse

Manuscript received 2 October 2017

First decision made 3 November 2017

Second decision made 9 January 2018

Third decision made 4 February 2018

Manuscript accepted 10 February 2018 